\title{
Hepatitis C Virus Infection in Children and Pregnant Women: An Updated Review of the Literature on Screening and Treatments
}

\author{
Rosalia Ragusa, MD, $\mathrm{PhD}^{1}$ Liberato Simone Corsaro, $\mathrm{MSc}^{2}$ Evelise Frazzetto, $\mathrm{MD}^{3}$ \\ Emanuele Bertino, PharmD ${ }^{4}$ Maria Alessandra Bellia, MS-VI ${ }^{5 \odot}$ Gaetano Bertino, MD $^{3}$
}

\footnotetext{
${ }^{1}$ Health Technology Assessment Committee, Health Directorate, University Hospital "G. Rodolico," Catania, Italy

2 Department of Biomedical and Biotechnological Sciences, University of Catania, Catania, Italy

${ }^{3}$ Hepatology Unit, A.O.U. Policlinico-Vittorio Emanuele, Department of Clinical and Experimental Medicine, University of Catania, Catania, Italy

${ }^{4}$ Department of Drug Sciences, University of Catania, Catania, Italy

${ }^{5}$ School of Medicine, University of Catania, Catania, Italy
}

Am J Perinatol Rep 2020;10:e121-e127.

\author{
Address for correspondence Rosalia Ragusa, MD, PhD, Health \\ Technology Assessment Committee, University Hospital “G. \\ Rodolico,", Via Rosso di San Secondo, 3, Catania 95128, Italy \\ (e-mail: ragusar@unict.it).
}

\begin{abstract}
Keywords

- HCV infection

- mother-to-child transmission

- HCV screening

- direct-acting antivirals

- pregnant women

- perinatal outcome

- pregnancy outcome

Objective The aim of the paper is to review the current information relating to the diagnosis and treatment of hepatitis $\mathrm{C}$ virus (HCV) infection in pregnant women and children, particularly those infected by mother-to-child transmission.

Study Design A review of published literature was performed to identify relevant articles published between January 2015 and March 2019 on: HCV infection in pregnant woman, mother-to child-transmission of HCV and HCV infection in pediatrics. The results of the evaluation of the different studies were summarized in two sections describing separately the screening and effective treatments in pregnant women and children.

Results The rate of mother-to-child transmission of HCV is approximately $5 \%$. HCV infection is strongly associated with cholestasis and preterm birth. Prenatal diagnosis of hepatitis $C$ virus has a dual benefit for mother and child. Perinatally infected children develop cirrhosis in earlier age than those who acquire HCV as adolescents. Pregnant women with cirrhosis have a higher risk of poor maternal and neonatal outcomes than those without cirrhosis.

Conclusion To improve public health, universal screening of pregnant women for $\mathrm{HCV}$ infection should be performed. Early identification of women and children with HCV infection is important to enable them to be included in assessment and/or treatment programs.
\end{abstract}

Hepatitis $\mathrm{C}$ virus (HCV) is transmitted through percutaneous exposure to infected blood. Other routes include mother-tochild transmission (MTCT) and the sharing of contaminated devices for noninjection drug use. The recent widespread practices such as piercing, tattoo, or manicure among girls of childbearing age may increase the percentage of infected pregnant women. Using unsterilized needles or sharing object that may contain minimal traces of blood leads to the transmission of virus not well perceived by girls.

According to the U.S. Centers for Disease Control and Prevention, an estimated 23,000 to 46,000 children in the United States live with HCV infection. Notably, children born received

December 29, 2019

accepted after revision

February 20, 2020
DOI https://doi.org/

10.1055/s-0040-1709185. ISSN 2157-6998.
Copyright $\odot 2020$ by Thieme Medical Publishers, Inc., 333 Seventh Avenue, New York, NY 10001, USA. Tel: +1(212) 760-0888.
License terms

(요 (1) $\circledast$ 
to HCV-positive mothers are at particular risk of HCV infection. Africa is hyperendemic with respect to viral hepatitis $B$ and $C$ infections, with a prevalence of detectable HCV viral load of $62.3 \%$ in HCV-positive pregnant women. Infected mothers have a high potential for transmission to their children. ${ }^{1}$

Screening for the presence of HCV, with selection of individuals on the basis of demographics, possible exposure, high-risk behavior, and medical conditions, is very important. Screening is justified by high HCV prevalence in particular populations, the association of treatment with a reduction of the risk of hepatocellular carcinoma and of all-cause mortality, and the public-health benefits of limiting HCV transmission by early treatment, viral clearance, and modification of risk behaviors. ${ }^{2}$

Prenatal diagnosis of hepatitis $\mathrm{C}$ virus has a dual benefit for mother and child. HCV screening should be performed in all pregnant women to diagnose an unacknowledged infection by the mother which could, with new treatments available today, be eradicated or, definitely, allow a better quality of life. Furthermore, screening during pregnancy discloses an exposure of the newborn, previously unknown, to the virus.

If the screening gives a positive response, prompt immunoprophylactic measures and close follow-up after the birth, are mandatory.

The aim of the paper is to review the current information relating to the diagnosis and treatment of HCV infection in pregnant women and in children, particularly those infected by MTCT. We have evaluated the existing knowledge relating to HCV treatment in children and pregnant women and outlined the evidence that currently supports the clinical decision-making.

\section{Materials and Methods}

The systematic review will include relevant articles on HCV infection in pregnant woman, mother to child transmission of $\mathrm{HCV}$, and HCV infection in pediatrics.
This work has been done to detect and eliminate incorrect behaviors or to adopt virtuous behaviors, for proper management of HCV infection, in these two particular sets of patients.

An electronic search of the literature relating to $\mathrm{HCV}$ infection and treatment was performed within the PubMed, Scopus, and Web of Science databases, using the following keywords: "HCV," "pregnant women," "pregnancy," "children," "MTCT," "screening," and "direct-acting antivirals." First "HCV" was matched with the other terms, then "children" and "direct-acting antivirals" were matched with the others terms. All the best matches were included.

Articles published between January 2015 and March 2019 inclusive were searched.

Additional publications were identified by manually searching within reference lists of the retrieved articles. Among the identified studies concerning the treatment of hepatitis $C$ in pregnancy and in children, all titles and abstracts were reviewed, and appropriate papers were assessed for inclusion. Case reports, editorials, unpublished data from conference abstracts, studies not written in English, and irrelevant studies were all excluded.

We used a scale for assessing the quality of published nonrandomized studies in meta-analyses, called the Newcastle-Ottawa-scale. We used the Newcastle-Ottawa Quality Assessment scale for cohort studies with three groups of items: selection, comparability, and outcome for assessing the quality of published nonrandomized studies in meta-analyses. For each item a series of response options are provided. A final set of 65 recent publications describing prospective, controlled studies, reviews or meta-analyses with a relevant number of patients was included, as shown in - Fig. 1.

The objectives of the study were to search for data and to provide updated information on the epidemiology and clinical problems relating to the treatment of HCV infections in pregnant women (primary objective) and individuals $<18$-years old (secondary objective).

The results of the evaluation of the different studies will be summarized in two sections describing separately the

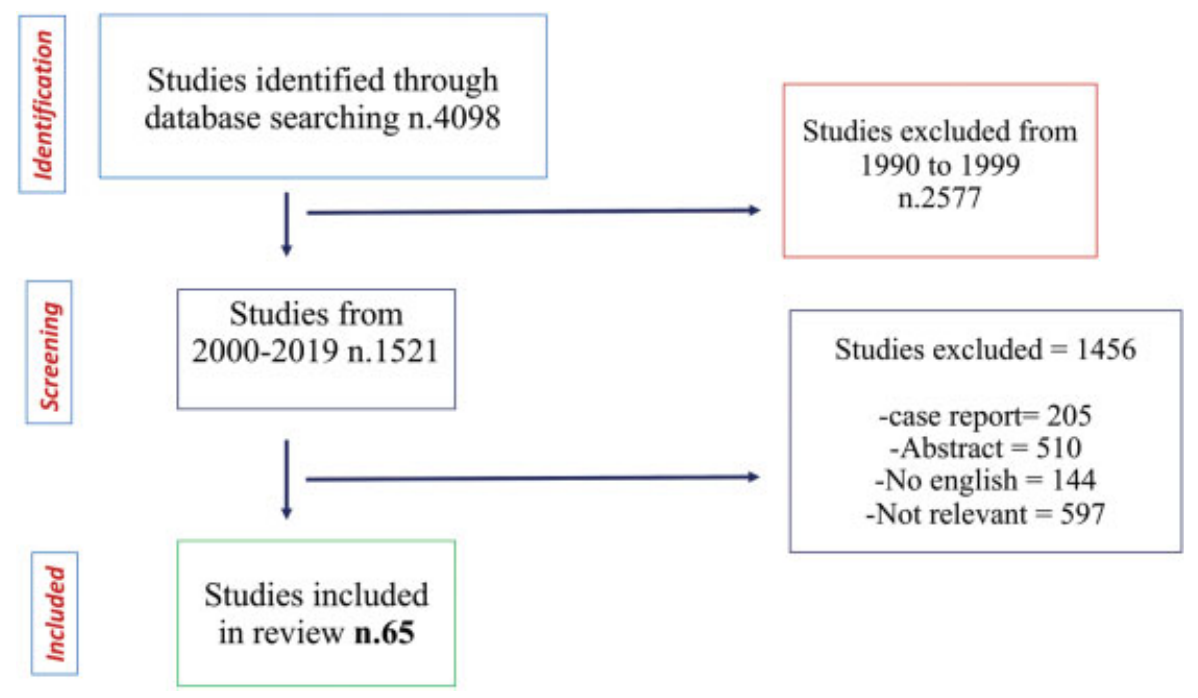

Fig. 1 Study selection process. 
screening and effective treatments in pregnant women and children.

\section{Results}

\section{Treatment of Pregnant Women with HCV Infection}

The prevalence of HCV infection is on the rise among young adults, including women of childbearing age, ${ }^{3}$ and the screening of pregnant women is becoming increasingly important. ${ }^{4}$ The prevalence of serum anti-HCV antibodies in pregnant women has been estimated in studies of large cohorts to be 0.1 to $3.6 \% .^{5}$

From 2011 to 2016, among women of childbearing age in the United States, HCV testing increased by $39 \%$, and positivity increased by $36 \%{ }^{6}$ The introduction of routine screening for pregnant women has led to the increased detection of $\mathrm{HCV}$ in women who do not present with infection risk factors. In Poland, the introduction of routine screening in 2010 was associated with an increase in the percentage of HCV-positive women who were diagnosed during pregnancy (as opposed to before or after pregnancy). ${ }^{7}$ Compared with universal screening of pregnant women, risk-factor-based screening is not effective. ${ }^{8}$

Vertical transmission of HCV occurs in 5 to $15 \%$ of pregnant women infected with the virus. MTCT progresses in 3 to $5 \%$ of cases toward chronic infection in children. ${ }^{9}$ Breastfeeding is not a risk factor for HCV MTCT. ${ }^{10}$ However, it is important that HCV-infected women who breastfeed abstain from doing so while their nipples are cracked, damaged, or are bleeding, and if they have human immunodeficiency virus/HCV coinfection.

$\mathrm{HCV}$ vertical transmission in intracytoplasmic sperm injection, seemed to be of low incidence in polymerase chain reaction (PCR) positive women, while in case of HCV PCR negative/seropositive women, it appeared completely absent. ${ }^{11}$

Hepatitis C virus infection is frequent in HIV-infected persons. Unlike coinfection with HIV and hepatitis B virus (HBV), which does not affect the risk of prenatal complications, in case of coinfection with HIV and HCV there is a higher percentage of complications of pregnancy compared with HIV infection only. These coinfections are associated with adverse pregnancy outcomes with higher risk of obstetrical complications. Emergency cesarean section, preeclampsia, stillbirth, very preterm delivery, and very low birthweight are described. ${ }^{12}$

HCV infection remained strongly associated with cholestasis and preterm birth. The incidence of preterm birth is statistically significant (1.6 and $5.7 \%$ of cases). ${ }^{12}$

HCV ribonucleic acid (RNA) levels can fluctuate during pregnancy and the postpartum period, ${ }^{13}$ most likely as a result of the release of tolerance in HCV-specific T-lymphocyte responses that develop during pregnancy.

HCV-infected patients should be treated with antiviral therapy, with the goal of achieving a sustained virologic response (SVR), preferably early in the course of chronic HCV infection, prior to the development of severe liver disease and other complication. Achievement of SVR prevents additional HCV-related liver damage ${ }^{14}$ and is associated with $>70 \%$ reduction of the risk of hepatocellular carcinoma
(HCC), and 90\% reduction of the risk of mortality and liver transplantation. ${ }^{15,16}$ SVR is positively associated with quality of life, ${ }^{17}$ as indicated by physical, emotional, and social health status. ${ }^{18,19}$

The safety of direct-acting antivirals (DAAs) administration during pregnancy, including possible effects on fertility, is not yet known. ${ }^{20}$ If women become pregnant while receiving DAAs therapy (with or without ribavirin), their physicians should discuss with them the risks and benefits of continuing treatment. In this regard, in a survey of 141 women with a history of $\mathrm{HCV}, 60 \%$ indicated a willingness to take antepartum DAAs therapy to lower the risk of MTCT. $^{21}$ By contrast, only $21 \%$ were willing to take DAAs therapy during pregnancy for self-cure even if it did not affect MTCT, although among the women who were not willing to do so, $20 \%$ responded that they might change their minds if more data were available for human trials regarding the use of DAAs during pregnancy. Having a previous history of taking DAAs was associated with a willingness to take DAAs during pregnancy.

Serum levels of alanine aminotransferase (ALT) decrease during the first and third trimesters of pregnancy and increase after childbirth, whereas levels of HCV RNA increase during the first and third trimesters and decrease after delivery. These changes probably result from the immunosuppressive effects of pregnancy.

Maternal HCV infection is associated with high risk of adverse perinatal outcome. ${ }^{22}$ Studies reported a higher incidence of intrauterine fetal death (3.4\%), small for gestational age $(11.3 \%)$, low birthweight $(12,5 \%)$, or very low birthweight. ${ }^{23}$ There are also reported low Apgar score at 5 minutes, admission to the neonatal intensive care unit, up to an increase in neonatal mortality. ${ }^{24}$

Among the complications described in the obstetric outcome, between HCV positive females we find: higher rate of cesarean section and in vacuum delivery, higher rates of pre and postpartum hemorrhagic anemia, premature rupture of the membranes, blood transfusion. Gestational diabetes, hypertension, and a greater number of hospitalizations are described.

Preterm birth, low birthweight, and congenital anomalies seem to be caused by virus infection. We must not forget, however, that other concomitant risk factors, such as alcohol and drugs, can generate the same effects. ${ }^{25-27}$

The incidence of intrahepatic cholestasis of pregnancy (ICP) is higher in pregnant women with HCV infection than in those without infection, ${ }^{28}$ and ICP is associated with high rates of adverse maternal and fetal outcomes. ${ }^{29}$

Furthermore, pregnant women with cirrhosis are at high risk for poor maternal outcomes (preeclampsia, caesarean section, hemorrhagic complications and death) and neonatal outcomes (preterm delivery, low birthweight and neonatal death). ${ }^{30-32}$

\section{Treatment of Children with HCV Infection}

Anti-HCV antibodies (anti-HCV Ab) can be transmitted across the placenta from a pregnant woman to the fetus and maternal antibody can be detected in the serum of babies born to positive mothers, up to 13 months after birth. An 
elevated antibody titer in newborn serum is not indicative of neonatal infection. To diagnose HCV infection in children the PCR, for the detection of HCV RNA, is the choice test.

The American Academy of Pediatrics and Center for Diseases Control recommends screening of infants born to HCVpositive women for anti-HCV Ab after 18 months of age. Diagnosis can be anticipated with two positive results of HCV RNA research in patients $>1$ month of age. ${ }^{33}$

It has been estimated that approximately 5 million children worldwide have an active HCV infection. Results from the National Health and Nutrition Examination Survey indicated that $0.2 \%$ of 6 to 11 -year-olds and $0.4 \%$ of 12 to 19 -yearolds are chronically infected with HCV. ${ }^{34}$ From 2011 to 2016 in the United States, HCV testing among children increased by $25 \%$ (from 0.47 to $0.59 \%$ ), and positivity increased by $13 \%$ (from 3.6 to $4.0 \%)^{7}$ The main risk factors for HCV infection in children are tumors, transfusions, and related treatments, ${ }^{35,36}$ and having a mother with HCV infection. ${ }^{37}$ The risk of MTCT of HCV is associated with maternal HIV coinfection, and with maternal HCV RNA levels. Avoiding the use of fetal scalp electrodes and iatrogenic birth trauma can reduce HCV MTCT. ${ }^{38}$ Approximately 25 to $50 \%$ of infected children spontaneously resolve HCV infection from 3 years of age for previously detectable HCV RNA loss. ${ }^{39}$

Perinatally infected children develop cirrhosis at a far earlier age than those who acquire HCV as adolescents through other means. ${ }^{40}$

The detection rate of perinatal HCV is low because of a lack of screening, slow onset of symptoms, and poor adherence to the requirement for 18 months of follow-up after birth. ${ }^{41}$ Although serum aminotransferase levels are often elevated, children $<3$ years of age with HCV infection do not have advanced liver disease.

The staging of hepatitis $C$ in children can be achieved through objective examination and the evaluation of routine laboratory parameters, including albumin, serum aminotransferase levels, total bilirubin, international normalized ratio, and platelet counts, every 6 to 12 months. Serum fibrosis markers can enable assessment of disease severity, but their utility requires further confirmation. ${ }^{42}$ Serum aminotransferase levels often do not reflect the severity of the disease in children, who might, for instance, have a normal aminotransferase level, despite a biopsy revealing significant necroinflammation. Hepatic histology remains the gold standard as a prognostic tool, as it can provide information on the progression of liver disease, but liver biopsy has some limitations: is an invasive examination, there may be sampling errors and interobserver variability.

To overcome these limitations, new methods based on imaging studies assisted by combinations of biomarkers, are preferred. ${ }^{43}$ Ultrasonographic liver elastography in children requires the use of specialized probes and threshold values for advanced fibrosis/cirrhosis that differ from those used in adults; nevertheless, this approach seems promising for the monitoring of children with chronic HCV infection. ${ }^{44}$

The progression of fibrosis in children with HCV infection is slow, with low levels of advanced liver disease observed up to 20 years after MTCT. However, children with comorbidities such as obesity with nonalcoholic fatty liver disease and those receiving hepatotoxic drugs should be monitored closely for disease progression. ${ }^{45,46}$ HCC is rarely found in children, and among them it has been reported almost exclusively in children with cirrhosis. Children with chronic HCV infection and a history of childhood leukemia may be at a higher risk of developing HCC. ${ }^{47}$ Endoscopy is necessary to detect esophageal varices in children with cirrhosis.

The treatment of HCV infection in children has rapidly evolved away from interferon regimens and toward DAAs that have safer and more efficacious drug profiles. ${ }^{48}$ While we still await the results of the first vaccine efficacy study, DAA regimens are now available for children $\geq 12$-years old. ${ }^{49}$

In 2017, the U.S. Food and Drug Administration (FDA) and the European Medicines Agency (EMA) approved a fixeddose DAA combination of sofosbuvir and ledipasvir, as well as the combination sofosbuvir plus ribavirin, for the treatment of adolescents (12-17-years old) with chronic hepatitis C. ${ }^{50}$ Preliminary results on the use of DAAs in pediatric patients are available for the fixed-dose combination sofosbuvir and ledipasvir in children aged 6 to 17 years for genotype 1 or 4 infection. ${ }^{51,52}$ In HCV-infected 12 to 17 year-olds who received oral fixed-dose combinations of sofosbuvir and ledipasvir daily for 12 weeks, tests for HCV RNA gave negative results in all patients at weeks 8 and 12 and at SVR12. ${ }^{53}$ In these patients, asthenia was the most common adverse effect, followed by headache. No symptoms related to the cardiovascular system or cases of symptomatic bradycardia/syncope were reported. ${ }^{54}$

The FDA and the EMA have also approved a combination of sofosbuvir plus ribavirin for adolescents 12 to 17-years old with genotype 2 or $3 \mathrm{HCV}$ infection, as well as a combination of ombitasvir, paritaprevir, and ritonavir with or without dasabuvir and with or without ribavirin for adolescents 12 to 17-years old with genotype 1 or 4 infections, and a combination of sofosbuvir plus daclatasvir for children with genotype 4 infection. The safety and efficacy term of the sofosbuvir plus daclatasvir combination has been demonstrated in 8 to 18-year-olds with genotype $4 \mathrm{HCV}$ infection. ${ }^{55}$

On April 30, 2019, the FDA approved the combination of glecaprevir and pibrentasvir for the treatment of 12 to 17year-olds who are infected with any of the six identified HCV genotypes, either without cirrhosis or with compensated cirrhosis. The safety and efficacy of glecaprevir-pibrentasvir in pediatric patients was evaluated in clinical trials of 47 patients with genotype $1,2,3$, or $4 \mathrm{HCV}$ infection without cirrhosis or with mild cirrhosis. These patients received glecaprevir-pibrentasvir for 8 or 16 weeks, and no virus was detected in the blood 12 weeks after finishing treatment. In pediatric patients with cirrhosis, a history of kidney and/or liver transplantation, or genotype 5 or $6 \mathrm{HCV}$ infection, the safety and efficacy of glecaprevir-pibrentasvir are supported by the results of previous studies in adults. The adverse reactions observed (headache and fatigue) were consistent with those observed in clinical studies in adults. 


\section{Discussion}

Both children and pregnant women have specific diseasemanagement strategies for HCV infection. Early identification and treatment of affected individuals can maximize health benefits.

Limited data are available on the burden of hepatitis $\mathrm{C}$ among pregnant women, indicating the need for further investigation of the role of therapy to treat $\mathrm{HCV}$ infection during pregnancy. To estimate the real prevalence of HCVinfected women during pregnancy, using a screening questionnaire to identify women at risk for HCV infection seems to be less effective than universal screening (HCV antibody test) for all pregnant women.

The widespread practices among young women at risk of HCV transmission require us to abandon the old concept of category at risk. As Kushner et al suggest we have to resign from risk-based screening because it has never been proven to be effective. ${ }^{56}$ Moreover, recent models of Pharmacoeconomics suggest that the adoption of universal screening for HCV in prenatal care would have undoubted advantages on the outcome of mother, newborn and is a cost-effective practice. ${ }^{57}$

In women of childbearing age who are infected with $\mathrm{HCV}$, antiviral treatment prior to pregnancy can improve maternal health and eliminate the risk of MTCT. Prevention of MTCT is limited by the absence of universal guidelines for HCV screening during pregnancy. ${ }^{58}$

A frequently observed trend associated with HCV infection consists of a steady rise in HCV RNA levels during pregnancy, followed by a decrease in the postpartum period, during which HCV RNA may become undetectable or return to prepregnancy levels. The possibility of spontaneous viral clearance should be monitored in all women who are evaluated for treatment with DAAs in the postpartum period. MTCT has been described only in HCV RNA positive women. ${ }^{12}$ Pregnancy does not appear to have an adverse effect on chronic HCV infection. Breastfeeding is not a risk factor for HCV MTCT.

Obstetric care provider must remember that the association of HCV and HIV positivity is not uncommon. In the light of common risk factors, it is suggested to perform screening for other sexually transmitted diseases, including HIV, syphilis, gonorrhea, chlamydia, and HBV in all HCV-positive pregnant women.

The staff must be trained to carry out the same maneuvers that are performed in HIV-positive patients in the care of childbirth and newborn to avoid the transmission of viruses to the newborn baby and also to the health care staff. ${ }^{59}$

Unlike most nosocomial infections, that are transmitted by staff hands, ${ }^{60,61}$ transmission of HCV infection, in health care systems, can only occur in special close relationships with the patient's blood. Infected women HCV RNA negative does not appear to transmit disease in utero; however, internal fetal monitoring, prolonged membrane rupture, episiotomy are not recommended. ${ }^{62}$ Amniocentesis must be preferred to chorionic villus sampling. Although it has not yet been clarified whether elective cesarean section can reduce the risk of HCV MTCT, elective cesarean delivery should be ethically justified to decrease global HCV transmission. ${ }^{63}$
In the case of women with pre-existing antibodies but HCV RNA negative, artificial insemination may also be considered safe. Transmission cases have been described only in case of positive PCR $\left(\mathrm{HCV} \mathrm{RNA}^{+}\right) .^{11}$

Unlike what is supposed for pregnant women, for whom it is suggested to extend the detection of antibodies to all of them, among children it is considered useful to perform HCV testing for those who are in the categories with greater risk of infection (children with tumors, transfusions, and related treatments or having a mother with HCV infection).

Early diagnosis and treatment of childhood HCV infection is recommended, because of possible effects on cirrhosis and mortality in individuals who acquire HCV through MTCT. Perinatally infected children develop cirrhosis earlier than those who acquire HCV as adolescents. If HCV-exposed infants are not adequately screened many pediatric HCV infections remain undetected. ${ }^{64}$

The best test to determine neonatal HCV positivity is serum HCV RNA assessment, because the persistence of maternal anti-HCV antibodies up to 18 months can produce false-positive results in antibody tests.

Following MTCT, negative HCV RNA test results for $>6$ months might be a more reliable proof of seroconversion. Newborns should be followed to rule out infection. The utility of obtaining a second RNA after an initial negative RNA performed after 2 months is uncertain, and its added value should be further assessed. ${ }^{65}$ It has been suggested that children with these negative results could receive antiviral therapy when the HCV viral load rises substantially, even in the presence of normal ALT levels. Another point of view favors waiting in this situation, because hepatic inflammation might again revive the child's immunity and lead to seroconversion. ${ }^{66}$ From full assessment of a child with HCV infection, other causes of liver disease must be excluded.

Tests for HBV, hepatitis A virus, and HIV immunity are essential to eliminate the possibility of coinfection and to identify any unimmunized children who may have not received routine childhood vaccination against HAV and HBV.

The early diagnosis and treatment of childhood HCV was recommended because cirrhosis and liver cancer occurred and significantly impacted mortality in individuals who acquired HCV through MTCT. Cirrhosis was the only risk factor that increased mortality in patients with childhood HCV infection.

Because there is no vaccine to prevent HCV infection, the clinical focus is primarily on treatment. Interferon-based regimens have limited success in children, especially those with genotype 1 or $4 \mathrm{HCV}$ infection. ${ }^{67,68}$ Treatment with interferon and the nucleoside analogue ribavirin has specific general and pediatric toxicities (such as temporary growth impairment) that do not occur with DAAs regimens. ${ }^{69}$ The FDA has approved glecaprevir-pibrentasvir as a treatment for HCV infections involving all six genotypes, but currently there are no approved treatment regimens for children $<12$ years of age).

\section{Conclusion}

Pregnant women infected with HCV carry an approximately $5 \%$ risk of transmission from mother to infant. 
To improve public health, universal screening of pregnant women for HCV infection should be performed. Early identification of women and children with HCV infection is important to enable them to be included in assessment and/or treatment programs. Identification of individuals who are at risk of infection, combined with measures to reduce behavior that is likely to increase this risk, can benefit public health. The recent simulation model demonstrated that universal prenatal hepatitis $C$ screening improves health outcomes in women with HCV infection, improves identification of HCV exposure in neonates born at risk, and is cost-effective.

Further observational studies on HCV infection in pregnant women and descriptions of successful treatments of HCV in children $<12$ years of age are needed to assess the occurrence of long-term complications in these populations.

\section{Funding}

This study was funded by the 2016/2018 Research Plan of University of Catania, Department of Clinical and Experimental Medicine (project "Early molecular and clinicalinstrumental markers in metabolic and chronic-degenerative pathologies").

\section{Conflict of Interest}

The authors declare that they have no conflict of interest.

\section{References}

1 Bigna JJ, Kenne AM, Hamroun A, et al. Gender development and hepatitis B and C infections among pregnant women in Africa: a systematic review and meta-analysis. Infect Dis Poverty 2019;8 (01):16

2 Gupta E, Bajpai M, Choudhary A. Hepatitis C virus: screening, diagnosis, and interpretation of laboratory assays. Asian J Transfus Sci 2014;8(01):19-25

3 Watts T, Stockman L, Martin J, Guilfoyle S, Vergeront JM. Increased risk for mother-to-infant transmission of hepatitis $C$ virus among medicaid recipients-Wisconsin, 2011-2015. MMWR Morb Mortal Wkly Rep 2017;66(42):1136-1139

4 Prasad MR. Hepatitis C virus screening in pregnancy: is it time to change our practice? Obstet Gynecol 2016;128(02):229-230

5 Dibba P, Cholankeril R, Li AA, et al. Hepatitis C in pregnancy. Diseases 2018;6(02):E31

6 Schillie SF, Canary L, Koneru A, et al. Hepatitis C virus in women of childbearing age, pregnant women, and children. Am J Prev Med 2018;55(05):633-641

7 Aniszewska M, Pokorska-Śpiewak M, Kowalik-Mikołajewska B, Pluta M, Marczyńska M. Hepatitis C infection among pregnant women in central Poland: significance of epidemiological anamnesis and impact of screening tests to detect infection. Adv Clin Exp Med 2019;28(03):313-318

8 Waruingi W, Mhanna MJ, Kumar D, Abughali N. Hepatitis C virus universal screening versus risk based selective screening during pregnancy. J Neonatal Perinatal Med 2015;8(04):371378

9 Jhaveri R, Hashem M, El-Kamary SS, et al. Hepatitis C virus (HCV) vertical transmission in 12-month-old infants born to HCVinfected women and assessment of maternal risk factors. Open Forum Infect Dis 2015;2(02):ofv089

10 Compagnone A, Catenazzi P, Riccardi R, Zuppa AA. Mother-tochild transmission of hepatitis C virus. Minerva Pediatr 2019;71 (02):174-180
11 Nesrine F, Saleh H. Hepatitis C virus (HCV) status in newborns born to $\mathrm{HCV}$ positive women performing intracytoplasmic sperm injection. Afr Health Sci 2012;12(01):58-62

12 Benhammou V, Tubiana R, Matheron S, et al; ANRS CO1/CO11-EPF French Perinatal Cohort study group. HBV or HCV coinfection in HIV1-infected pregnant women in France: prevalence and pregnancy outcomes. J Acquir Immune Defic Syndr 2018;77(05):439-450

13 Lin $\mathrm{HH}$, Kao JH. Hepatitis C virus load during pregnancy and puerperium. BJOG 2000;107(12):1503-1506

14 Coppola N, De Pascalis S, Pisaturo M, et al. Sustained virological response to antiviral treatment in chronic hepatitis $C$ patients may be predictable by HCV-RNA clearance in peripheral blood mononuclear cells. J Clin Virol 2013;58(04):748-750

15 Calvaruso V, Cabibbo G, Cacciola I, et al; Rete Sicilia Selezione Terapia-HCV (RESIST-HCV). Incidence of hepatocellular carcinoma in patients with $\mathrm{HCV}$-associated cirrhosis treated with direct-acting antiviral agents. Gastroenterology 2018;155(02):411-421.e4

16 Cabibbo G, Celsa C, Calvaruso V, et al; Rete Sicilia Selezione Terapia-HCV (RESIST-HCV) and Italian Liver Cancer (ITA.LI.CA.) Group. Direct-acting antivirals after successful treatment of early hepatocellular carcinoma improve survival in HCV-cirrhotic patients. J Hepatol 2019;71(02):265-273

17 Ragusa R, Bertino G, Bruno A, et al. Evaluation of health status in patients with hepatitis $c$ treated with and without interferon. Health Qual Life Outcomes 2018;16(01):17

18 Boscarino JA, Lu M, Moorman AC, et al; Chronic Hepatitis Cohort Study (CHeCS) Investigators. Predictors of poor mental and physical health status among patients with chronic hepatitis $C$ infection: the Chronic Hepatitis Cohort study (CHeCS). Hepatology 2015;61(03):802-811

19 Gerber L, Estep M, Stepanova M, Escheik C, Weinstein A, Younossi ZM. Effects of viral eradication with ledipasvir and sofosbuvir, with or without ribavirin, on measures of fatigue in patients with chronic hepatitis C virus infection. Clin Gastroenterol Hepatol 2016;14(01):156-64.e3

20 Spera AM, Eldin TK, Tosone G, Orlando R. Antiviral therapy for hepatitis C: has anything changed for pregnant/lactating women? World J Hepatol 2016;8(12):557-565

21 Kushner T, Cohen J, Tien PC, Terrault NA. Evaluating women's preferences for hepatitis $C$ treatment during pregnancy. Hepatol Commun 2018;2(11):1306-1310

22 Huang QT, Huang $\mathrm{Q}$ Z Zhong $\mathrm{M}$, et al. Chronic hepatitis $\mathrm{C}$ virus infection is associated with increased risk of preterm birth: a meta-analysis of observational studies. J Viral Hepat 2015;22(12):1033-1042

23 Money D, Boucoiran I, Wagner E, et al. Obstetrical and neonatal outcomes among women infected with hepatitis $C$ and their infants. J Obstet Gynaecol Can 2014;36(09):785-794

24 Rezk M, Omar Z. Deleterious impact of maternal hepatitis-C viral infection on maternal and fetal outcome: a 5-year prospective study. Arch Gynecol Obstet 2017;296(06):1097-1102

25 Connell LE, Salihu HM, Salemi JL, August EM, Weldeselasse H, Mbah AK. Maternal hepatitis B and hepatitis C carrier status and perinatal outcomes. Liver Int 2011;31(08):1163-1170

26 Vitale SG, Marilli I, Rapisarda AM, et al. Cellular and biochemical mechanisms, risk factors and management of preterm birth: state of the art. Minerva Ginecol 2014;66(06):589-595

27 Vitale SG, Laganà AS, Muscatello MR, et al. Psychopharmacotherapy in pregnancy and breastfeeding. Obstet Gynecol Surv 2016;71 (12):721-733

28 Wijarnpreecha K, Thongprayoon C, Sanguankeo A, Upala S, Ungprasert P, Cheungpasitporn W. Hepatitis C infection and intrahepatic cholestasis of pregnancy: a systematic review and meta-analysis. Clin Res Hepatol Gastroenterol 2017;41(01): 39-45

29 Belay T, Woldegiorgis H, Gress T, Rayyan Y. Intrahepatic cholestasis of pregnancy with concomitant hepatitis C virus infection, Joan C. Edwards SOM, Marshall University. Eur J Gastroenterol Hepatol 2015;27(04):372-374 
30 Puljic A, Salati J, Doss A, Caughey AB. Outcomes of pregnancies complicated by liver cirrhosis, portal hypertension, or esophageal varices. J Matern Fetal Neonatal Med 2016;29(03):506-509

31 Salman H, Shah M, Ali A, Aziz A, Vitale SG. Assessment of relationship of serum neurokinin-b level in the pathophysiology of preeclampsia: a case-control study. Adv Ther 2018;35(07):1114-1121

32 Chiofalo B, Laganà AS, Vaiarelli $A$, et al. Do miRNAs play a role in fetal growth restriction? A fresh look to a busy corner. BioMed Res Int 2017;2017:6073167

33 American Academy of Pediatrics. Recommendations for care of children in special circumstances: hepatitis C. In: Kimberlin DW, Brady MT, Jackson MA, Long SS, eds. Committee on Infectious Diseases. Red Book: 2015 Report of the Committee on Infectious Diseases. Elk Grove Village, IL: American Academy of Pediatrics; 2015:197

34 Denniston MM, Jiles RB, Drobeniuc J, et al. Chronic hepatitis C virus infection in the United States, National Health and Nutrition Examination Survey 2003 to 2010. Ann Intern Med 2014;160(05): 293-300

35 Dibenedetto SP, Ragusa R, Sciacca A, et al. Incidence and morbidity of infection by hepatitis $C$ virus in children with acute lymphoblastic leukaemia. Eur J Pediatr 1994;153(04):271-275

36 Dibenedetto SP, Miraglia V, Ippolito AM, et al. Reduction in the incidence of infection by hepatitis $C$ virus in children with acute lymphoblastic leukemia after suspension of sampling from the finger. Pediatr Infect Dis J 1996;15(03):265-266

37 Benova L, Mohamoud YA, Calvert C, Abu-Raddad LJ. Vertical transmission of hepatitis $C$ virus: systematic review and metaanalysis. Clin Infect Dis 2014;59(06):765-773

38 Dunkelberg JC, Berkley EM, Thiel KW, Leslie KK. Hepatitis B and C in pregnancy: a review and recommendations for care. J Perinatol 2014;34(12):882-891

39 Mast EE, Hwang LY, Seto DS, et al. Risk factors for perinatal transmission of hepatitis $\mathrm{C}$ virus (HCV) and the natural history of $\mathrm{HCV}$ infection acquired in infancy. J Infect Dis 2005;192(11):1880-1889

40 Modin L, Arshad A, Wilkes B, et al. Epidemiology and natural history of hepatitis $C$ virus infection among children and young people. J Hepatol 2019;70(03):371-378

41 Towers CV, Fortner KB. Infant follow-up postdelivery from a hepatitis $C$ viral load positive mother. J Matern Fetal Neonatal Med 2019;32(19):3303-3305

42 Mack CL, Gonzalez-Peralta RP, Gupta N, et al; North American Society for Pediatric Gastroenterology, Hepatology, and Nutrition. NASPGHAN practice guidelines: diagnosis and management of hepatitis $\mathrm{C}$ infection in infants, children, and adolescents. J Pediatr Gastroenterol Nutr 2012;54(06):838-855

43 Pokorska-Śpiewak M, Kowalik-Mikołajewska B, Aniszewska M, Pluta M, Marczyńska M. Is liver biopsy still needed in children with chronic viral hepatitis? World J Gastroenterol 2015;21(42): 12141-12149

44 Behairy Bel-S, Sira MM, Zalata KR, Salama SE, Abd-Allah MA. Transient elastography compared to liver biopsy and morphometry for predicting fibrosis in pediatric chronic liver disease: does etiology matter? World J Gastroenterol 2016;22(16):4238-4249

45 Kodhelaj K, Resuli B, Petrela E, Malaj V, Jaze H. Non-alcoholic fatty liver disease and non-alcoholic steatohepatitis in Albanian overweight children. Minerva Pediatr 2014;66(01):23-30

46 Fioredda F, Gigliotti AR, Haupt R, et al. HCV infection in very-longterm survivors after cancer chemotherapy and bone marrow transplantation: a single-center experience. J Pediatr Hematol Oncol 2005;27(09):481-485

47 González-Peralta RP, Langham MR Jr, Andres JM, et al. Hepatocellular carcinoma in 2 young adolescents with chronic hepatitis C. J Pediatr Gastroenterol Nutr 2009;48(05):630-635

48 Karnsakul W, Schwarz KB. Management of hepatitis C infection in children in the era of direct-acting antiviral agents. J Viral Hepat 2019;26(09):1034-1039
49 Ohmer S, Honegger J. New prospects for the treatment and prevention of hepatitis $C$ in children. Curr Opin Pediatr 2016;28 (01):93-100

50 Indolfi G, Serranti D, Resti M. Direct-acting antivirals for children and adolescents with chronic hepatitis C. Lancet Child Adolesc Health 2018;2(04):298-304

51 Murray KF, Balistreri WF, Bansal S, et al. Safety and efficacy of ledipasvir-sofosbuvir with or without ribavirin for chronic hepatitis C in children ages 6-11. Hepatology 2018;68(06):2158-2166

52 Alkaaby BA, Al-Ethawi AE. The effectiveness of oral antiviral (sofosbuvir/ledipasvir) in treating children with HCV infection. Pak J Med Sci 2018;34(06):1353-1356

53 El-Karaksy H, Mogahed EA, Abdullatif H, et al. Sustained viral response in genotype 4 chronic hepatitis $C$ virus-infected children and adolescents treated with sofosbuvir/ledipasvir. J Pediatr Gastroenterol Nutr 2018;67(05):626-630

54 Ghobrial C, Sobhy R, Mogahed E, Abdullatif H, El-Karaksy H. Is sofosbuvir/ledipasvir safe for the hearts of children with hepatitis C virus? Dig Liver Dis 2019;51(02):258-262

55 Abdel Ghaffar TY, El Naghi S, Abdel Gawad M, et al. Safety and efficacy of combined sofosbuvir/daclatasvir treatment of children and adolescents with chronic hepatitis C genotype 4. J Viral Hepat 2019;26(02):263-270

56 Kushner T, Chappell CA, Kim AY. Testing for hepatitis $C$ in pregnancy: the time has come for routine rather than risk-based. Curr Hepatol Rep 2019;18(02):206-215

57 Tasillo A, Eftekhari Yazdi G, Nolen S, et al. Short-term effects and long-term cost-effectiveness of universal hepatitis $C$ testing in prenatal care. Obstet Gynecol 2019;133(02):289-300

58 Hong J, Kushner T, Dieterich D, et al. Reducing mother-to-child transmission of HCV: is it attainable with a multidisciplinary approach? J Hepatol 2019;71(01):229-230

59 Marranzano M, Ragusa R, Platania M, Faro G, Coniglio MA. Knowledge, attitudes and practices towards patients with HIV/ AIDS in staff nurses in one university hospital in Sicily. Epidemiol Biostat Public Health 2013;10(01):e8731-1-e8731-6

60 Ragusa R, Giorgianni G, Faro G, Lazzara A, Bellia MA, Marranzano M. Are visitors dangerous carriers of pathogens in the hospital? An observational study in an University Hospital in Sicily. Hosp Top 2019;97(03):80-86

61 Ragusa R, Giorgianni G, Lupo L, et al. Healthcare-associated Clostridium difficile infection: role of correct hand hygiene in cross-infection control. J Prev Med Hyg 2018;59(02):E145-E152

62 Hughes BL, Page CM, Kuller JA; Society for Maternal-Fetal Medicine (SMFM). Hepatitis $C$ in pregnancy: screening, treatment, and management. Am J Obstet Gynecol 2017;217(05):B2-B12

63 Elrazek A, Saab S, Foad M, et al. Ongoing transmission of HCV: should cesarean section be justified? Data mining discovery. J Transl Int Med 2017;5(01):27-33

64 Chappell CA, Hillier SL, Crowe D, Meyn LA, Bogen DL, Krans EE. Hepatitis C virus screening among children exposed during pregnancy. Pediatrics 2018;141(06):e20173273

65 Epstein RL, Sabharwal V, Wachman EM, et al. Perinatal transmission of hepatitis $C$ virus: defining the cascade of care. J Pediatr 2018;203:34-40.e1

66 Indolfi G, Mangone G, Bartolini E, Moriondo M, Azzari C, Resti M. Hepatitis C viraemia after apparent spontaneous clearance in a vertically infected child. Lancet 2016;387(10031):1967-1968

67 Bertino G, Ardiri A, Proiti M, et al. Chronic hepatitis C: this and the new era of treatment. World J Hepatol 2016;8(02):92-106

68 Falade-Nwulia O, Suarez-Cuervo C, Nelson DR, Fried MW, Segal JB, Sulkowski MS. Oral direct-acting agent therapy for hepatitis $C$ virus infection: a systematic review. Ann Intern Med 2017;166 (09):637-648

69 Nwaohiri A, Schillie S, Bulterys M, Kourtis AP. Hepatitis C virus infection in children: how do we prevent it and how do we treat it? Expert Rev Anti Infect Ther 2018;16(09):689-694 